\title{
POLICY MAKING IN DIVIDED GOVERNMENT A Pivotal Actors Model with Party Discipline
}

\author{
JOSEP M. COLOMER
}

\begin{abstract}
$\underline{\text { Abstract }}$
This article presents a formal model of policy decision-making in an institutional framework of separation of powers in which the main actors are pivotal political parties with voting discipline. The basic model previously developed from pivotal politics theory for the analysis of the United States lawmaking is here modified to account for policy outcomes and institutional performances in other presidential regimes, especially in Latin America. Legislators' party indiscipline at voting and multi-partism appear as favorable conditions to reduce the size of the equilibrium set containing collectively inefficient outcomes, while a two-party system with strong party discipline is most prone to produce 'gridlock', that is, stability of socially inefficient policies. The article provides a framework for analysis which can induce significant revisions of empirical data, especially regarding the effects of situations of (newly defined) unified and divided government, different decision rules, the number of parties and their discipline. These implications should be testable and may inspire future analytical and empirical work.
\end{abstract}

$\underline{\text { Key words }}$ : Macroeconomic policy-making, Divided government, Political parties

JEL: E60, E66, H70, H73, H77

UPF Research fields: Public Economics 


\section{Introduction}

The effectiveness of policy decision-making and the social satisfaction with its outcomes in regimes based upon divided powers between the President and the Congress have been submitted to critical scrutiny and have been the subject of controversial statements. ${ }^{1}$ This paper holds that legislators' individual freedom at voting and multipartism are favorable institutional conditions for effective decision-making and collectively satisfactory policy outcomes. More precisely, the formal analysis here developed supports the hypothesis that, in a situation of divided government, legislators with no party discipline -a setting similar to the United States - tend to produce more collectively satisfactory outcomes than multiparty systems with strong disciplined parties at voting --a feature more common, for instance, in some Latin American presidential democracies. Against some other previous sketches, it is also found that a two party system with strong party discipline tends to produce less satisfactory outcomes than any of the two settings previously considered. Incentives for party indiscipline at voting could thus be conceived as favoring effective and satisfactory institutional decision-making. The reduction of political pluralism to adversarial bipartism, in contrast, should be regarded as a source of ineffectiveness and unsatisfactory outcomes.

The argument does not imply a generally favorable judgment of party indiscipline that should be extended to any institutional context. Actually, a Congress dominated by individuals' preferences and voting decisions is likely to focus on narrow issues, localistic interests or logrolling of private favors, rather than on the provision of large-group public goods. Multipartism, in contrast, can be a better feature if it reflects appropriately the pluralism of citizens' preferences and relevant issues in the society. However, this article does not discuss this kind of desirable properties, but only the collective utility of decisions made by political representatives through inter-institutional cooperation.

The point is that if all legislators' preferences are aggregated into only two parties and these enforce strong internal discipline at voting, the resulting two policy preferences to deal with will be significantly distant from each other and the legislators will be 'entrenched' around them. Logically, in a Congress with only two disciplined parties decisions can only be made through hard-won unanimity agreements between two distant 
policy positions. Then it can be expected that confrontational and adversarial politics may prevail, parties can be able to block each other and, as a result, there can be stable unsatisfactory policies on many issues in spite of the existence of a legislative majority favoring policy change -the usual negative meaning of 'gridlock'. It is in this context of bipartism --and paraphrasing a well-known saying on corruption regarding government in general- that party indiscipline can be seen as the grease that oils the wheels of divided government. $^{2}$

The following analysis can be relevant for understanding different levels of effective decision-making and social satisfaction with institutional policy outcomes in different presidential regimes, especially comparing the United States with other countries, as well as for the design of institutions and rules fostering good democratic governance. I now provide a framework for analysis which may induce significant revisions of empirical data according to innovative categories. The model allows us to identify implications on the expected effects of situations of (newly defined) unified and divided government, different decision rules, the number of parties and institutional rules promoting more or les strong party discipline. These implications should be testable and may inspire future analytical and empirical work.

Basically, what is presented here is a formal model of policy decision-making in an institutional framework of separation of powers in which the main actors are pivotal political parties with voting discipline. Previous analyses of institutional factors of decision-making under divided government either have built formal models based on some peculiar characteristics of the United States institutional system or have developed a more informal discussion of alternative institutional formulas that can be found elsewhere. Here I draw upon one of the formal, parsimonious modeling that better fits the U.S. case, which derives from the pivotal actors theory as originally presented by Keith Krehbiel (1996, 1998; for extensions assuming imperfect information, see Cameron 2000). But regarding the original model, some of the decision rules are changed and, especially, the assumption that political party organizations are not highly constraining so as to allow individual pivotal legislators to vote according to their preferences is replaced with the assumption that disciplined political parties play a crucial role at selecting policy positions and voting. ${ }^{3}$ 
With these alternative assumptions it is possible to approach some of the characteristics that can be more frequently found in most presidential regimes outside the United States. In particular, the assumption of individual legislators with high freedom to vote on their own can be more realistic for settings with elections in single member districts or with high intra-party competition among individual candidates, like in the UnitedStates, while the assumption of party discipline seems more realistic when representatives are elected by proportional representation and closed party lists. Factors of party discipline may include the degree in which the central party leadership controls the use of the party label, the selection of candidates and their place in electoral lists, as proposed by Mainwaring and Shugart (1997). But the degree of central party control can also be considered to be an intermediate variable, which may depend to some extent on the degree of restriction that the electoral system imposes on the variety of potential divisive issues in the society and of citizens' preferences. In a highly complex society like the United States, a very restrictive electoral system based on single member districts with plurality rule has produced a very low number of parties which have developed low internal cohesion. Then, the members of Congress can be located -at least to the effects of analysis-- along a continuum of individual preferences. In contrast, in other societies elections by party list proportional representation tend to permit a variable number of parties with higher internal cohesion, whose members can keep higher discipline in Congress. ${ }^{4}$

The analysis here presented focuses on the relative collective utility that different policy outcomes derived from different institutional rules and political party configurations tend to produce. A number of formal findings allow us to identify some key institutional and political conditions in which efficient equilibrium outcomes can be expected, as well as to explain relatively bad performances of policy decision-making in situations of divided government when strong party discipline exists. Specifically, policy decision-making in divided government when only two disciplined parties are pivotal appears to be more prone to produce collectively inefficient outcomes in equilibrium than under the assumption that party discipline does not matter. With democratic party discipline, only a high number of parties is able to reduce the size of the equilibrium set containing collectively inefficient outcomes. In other words, under conditions of strong party voting discipline, multi-party 
systems can produce better policy decisions that two party systems, although not as good as those made in institutional settings in which political party discipline is weak or inexistent.

\section{The basic model}

The basic elements of the formal model to be developed are decision rules and pivotal actors. In the present version, they are the following:

\section{* Decision rules:}

In order to approve a bill, the process of decision making include the following steps. - A bill can be initially approved by simple majority of the members of the unicameral Congress, typically around the position preferred by the median legislator in case of no party constraints or around the median party preference when parties are disciplined. I call 'median party' the congressional disciplined party containing the median legislator and thus able to attract a majority of legislators in favor of its proposal. ${ }^{5}$

- The President may veto the bill.

- The Congress can override the presidential veto by some qualified majority rule. (The most typical override rule is $2 / 3$, but other rules, such as $3 / 5$ or the requirement of qualified majorities in two chambers, also exist in some countries). ${ }^{6}$

These rules imply that the Congress has no restrictions on amendments. Thus, the basic model to be developed can be enlightening regarding equilibrium outcomes for both ordinary legislation typically initiated by the Congress, the congressional discussion of presidential initiatives, and even legislative presidential decrees submitted to further congressional approval (in the latter case with some caveats regarding the effects of timing on the further location of the status quo after the decree is enforced). A common feature in all these procedures is that they allow the Congress to present, revise or reshape the bill according to the preference of the median legislator or the median party. The agenda setter is thus not relevant for the policy position which is going to be approved in equilibrium under the above mentioned set of rules and will not be included in the following discussion. ${ }^{7}$ 
* Pivotal actors:

As mentioned, I will compare results based on two alternative assumptions regarding pivotal actors: whether they can be individuals or disciplined political parties. If it is assumed that individuals vote according to their preferences, the pivotal actors for the above mentioned decision rules are:

- The Median legislator.

- The President.

- The Veto legislator.

The latter is the one that, by tipping on the side of the presidential veto, can prevent congressional override (the veto legislator should have a number of legislators on the President's side equals to one minus the override rule; for instance, under the $2 / 3$ override rule, the veto legislator is the one with $1 / 3$ of legislators on the President's side).

The alternative assumption of party discipline implies that the pivotal actors are the congressional parties, that is, groups of members of Congress with relatively close, contiguous preferences on the policy space that accept to act as a single actor (congressional groups of this kind are typically called 'bancadas' in Latin American Congresses). In the model, it is assumed that they work with what could be called democratic discipline, which requires two conditions: first, each congressional party makes an internally democratic decision on which policy preference to adopt, which typically corresponds to the preference of the party's median member; second, all party members vote according to the preference that has been adopted. ${ }^{8}$

According to the assumptions of party democratic discipline, the pivotal actors are the following:

- The Median party, that is, the party containing the median legislator. Under the above assumptions, the Median party's preference will be the one of the median party's member; in other words, the preference of the median legislator's party median member.

- The President's party, whose preference will be the one of the presidential party's median member. This may coincide or not with the President's preference as far as the members of the President's party, even if they are closer to the President's preference than to any other 
party's, have sufficient opportunities to adopt a collective preference by internal discussion and voting and to present the corresponding bills and amendments.

- The Veto party, that is, the party containing the veto legislator, whose preference can be referred to as the veto legislator's party median member's.

The model adopts the standard assumptions that all policy preferences can be located on a single-dimensional space, individual preferences are single-peaked and symmetric (so that individual utility decreases monotonically with the distance from individual's preference to the different policy positions), and actors have perfect information (and so no significant bargaining or other transaction costs are included in their decision functions).

In particular, the assumption of a single policy dimension has the important advantage of simplicity and readability without necessarily implying major losses in realism. According to some available empirical analyses, even in the U.S. Congress a single dimension can account for most of the variance in legislators' roll call voting (Poole and Rosenthal 1997, Cameron 2000). In spite of the absence of comparable data and analyses for congressional voting in other presidential regimes, it may be reasonable to assume that single-dimensionality can be stronger in multi-party systems with ideologically-oriented, disciplines parties than in the individually-driven U.S. Congress. Typically, a single ideological dimension, such as the left-right axis, contains multiple issues with disparate actors' preferences. As different agenda-setter models suggest, each party can choose to give salience or legislative priority to those issues on which it can expect to be able to adopt an advantageous position. But disciplined political parties rarely leapfrog each other, by this way establishing a linear continuum among them. Nevertheless, the present assumption of uni-dimensionality could be modified if empirical observation suggested that multidime nsionality can be relevant. (For a set of estimate party relative positions on a leftright single dimension, see Castles and Mair 1984, Huber and Inglehart 1995).

The following analysis focuses on the set of outcomes in equilibrium, or 'equilibrium set', and their collective efficiency as can be measured by their distance to the median legislator. The 'equilibrium set' is what Krehbiel and other authors using this kind of models have called 'gridlock interval' or similar expressions, but I want to avoid to focus 
on 'stalemate', 'deadlock' or 'gridlock' because the main interest of this paper is not whether policy stability is always better or worse than policy change, as it does not focus either on the process of inter-institutional conflict or bargaining. In the present approach, policy stability or 'gridlock' can be as good or as bad as policy change or instability depending on the utility or satisfaction that the corresponding outcomes can produce among the voters.

I adopt here the straightforward criterion that the most satisfactory outcomes are those that correspond to the median voter's preference, whatever the distribution of voters' preferences along the policy space. This is based upon the mathematical property that the median position minimizes the sum of the distances from all the other positions or preferences, which can be considered to be equivalent to the proposition that the median position maximizes collective satisfaction or the sum of individuals' satisfactions. (For the criterion of social utility based on closeness to the median voter's preference, see Davis, Hinich and Ordeshook 1970, Huber and Powell 1994, Hinich and Munger 1997, Powell 2000, Colomer 2001).

The outcomes to be found in equilibrium under different institutional settings and political party configurations will thus be discussed for their relative closeness to the median legislator's and the median party's preferences. I focus on the 'equilibrium set' (or 'gridlock interval') because it contains all the stable outcomes that can be achieved through a more or less long, more or less costly process of institutional decision-making. Then, socially satisfactory outcomes may be the result of either policy stability or policy change, as may unsatisfactory outcomes also be, depending on the locations of the initial status quo and the further outcome.

The reader should, however, keep always in mind that this is only a calculus of 'collective' utility based on political representatives' preferences. It is extremely important to note that the degree of correspondence between the political representatives' preferences and those of the voters, and in particular whether the median legislator's or the president's preferences correspond or not to the one of the median voter, highly depends on the electoral system, which is not explicitly included in the present model. Actually, it can be held that U.S.-type congressional electoral systems based upon single member districts and plurality rule with mal-apportionment and gerrymandering, features that are also partly reproduced in the U.S. -type presidential electoral college, tend to create more distance 
between the median legislator's or the president's preference and the median voter's preference than most electoral systems based on large distric ts with proportional representation or other inclusive electoral rules. 'Collective' utility as based upon political representatives' preferences should not thus be equated at all with 'social' utility based upon voters' preferences without accounting for the effects of the electoral system. I will be back to this in the final section of this paper.

\section{Revising the non party pivotal actors model}

The non-party pivotal actors model, as initially developed by Krehbiel for the analysis of the United States institutional process, can be revised and discussed as follows. First, it should be noted that under the assumptions of Krehbiel's original non-party pivotal actors model, presidential unified government strictu senso never exists. Even if the President has many supporters --that is, many legislators that can be relatively close to the presidential preference--, the President will always have to bargain an intermediate outcome with the Median legislator and the Veto legislator, who are not submitted to any collective discipline even if they belong to the President's party. ${ }^{9}$

Thus, party indiscipline always produces some kind of divided government in which intermediate compromises between the three pivotal actors can be achieved. As will be discussed immediately, the expected outcomes are the following. First, the Median legislator's preference if the decision is made from an initial status quo which is located on distant positions and is highly unsatisfactory for all three actors. Second, a relatively small and moderate 'equilibrium set' including non-median outcomes if the decision is made from some relatively less distant, less unsatisfactory initial status quos. The non-median equilibrium outcomes can be considered to be relatively moderate and satisfactory because they are located between the Median legislator's preference and either the Veto legislator's preference or the President's preference (the closer of these two actors to the median legislator). 
The corresponding formal model is presented in Figure 1. The horizontal axis represents all policy positions on which the status quo policy and the actors' preferences can be located -let's assume, for instance, that values close to zero represent leftist policy preferences while high values represent rightist ones. The President $(\mathrm{P})$, the Veto legislator (V) and the Median legislator (MeL) are represented as different points along the axis so as $\mathrm{P}<\mathrm{V}<\mathrm{MeL}$. Of course, inverse relative positions (assuming, for instance, that the President is the most rightwing of the pivotal actors) would produce analogous results in the following analysis.

The vertical axis indicates the outcomes that will be achieved by a process of decision-making according to the rules above presented from different initial status quos along the horizontal axis. Specifically, from any status quo located on the right of the Median legislator, the outcome will be the Median legislator's preference, since he will have the opportunity to present the corresponding bill, there will be a clear majority supporting the move, and the other pivotal actors will also increase their satisfaction with the new policy so they will not vetoed it. This result is indicated by the flat line in Interval IV placed at the level of the Median legislator's preference on the vertical axis.

From other initial status quos, the Veto legislator plays a more active pivotal role. The intervals separated by vertical lines in the graph are built upon symmetric distances from the Veto legislator to the Median legislator. It is supposed that the Veto legislator is indifferent to policies located at the same distance from his preference on any of the two sides of the policy spectrum. Thus, from an initial status quo located on the far left of the spectrum, the Veto legislator will be better off with a bill corresponding to the Median legislator's preference and will not support the hypothetical presidential veto (this, if it happened, would be override). This is valid until the point in which the status quo lies on the same distance to the Veto legislator from the left as his distance to the bill proposed by the Median legislator, as indicated by the flat line section in Interval I on the left of the graph.

In contrast to the collectively efficient outcomes corresponding to the Median legislators' preference that can be expected from the just identified two extreme sets of status quos, from more moderate initial status quos located around the Veto legislator's 
preference the outcomes will be different. The Veto legislator is indifferent to symmetric points around his preference, as mentioned, so he can accept symmetric transfers from any status quo located on his left to a new outcome located at the same distance on his right as can be proposed by the Median legislator. Many of these proposals may be vetoed by the President, but the Veto legislator and the legislators on his right will be able to override the presidential veto. The corresponding outcomes are represented by the decreasing line in Interval II on the left of the Veto legislator.

Finally, from status quos located between the Veto legislator and the Median legislator, policy change is not feasible. Any move from any of these points to the right will have a majority support but will be vetoed by the President and have the support of the Veto legislator so that the veto will not be override. The corresponding outcomes in equilibrium, or equilibrium set, is represented by the thick increasing line in Interval III.

The above analysis is somehow a simplified version of the one presented by Krehbiel in his original pivotal actors model. I am, however, interested in measuring the size of the equilibrium set (or gridlock interval) in order to evaluate the collective efficiency of the policy outcomes of this process. As have been seen, from many initial status quos corresponding to the preferences of a majority of legislators, collectively efficient outcomes corresponding to the Median legislator's preference are achieved in equilibrium. The non-median outcomes that are achieved from less unsatisfactory initial status quos are located between the Median legislator's and the Veto legislator's preferences. So assuming that proportions of legislators' preferences can be counted along the horizontal axis, from zero on the left to one on the extreme right, the 'size' of the equilibrium set including all stable policy outcomes will be:

Equilibrium set $=\mathrm{MeL}-\mathrm{V}$

where:

MeL: Median legislator's preference;

$\mathrm{V}$ : Veto legislator's preference. 
Proposition 1. Under the assumption of no party discipline, the equilibrium set, or set of stable outcomes, includes all the policy preferences between the Median legislator's and the Veto legislator's.

For alternative locations of the pivotal actors implying that the Median legislator is closer to the President than to the Veto legislator, it would be sufficient to substitute the President for the Veto legislator, so that the size of the equilibrium set would be the distance between MeL and P.

For symmetric locations of the actors, so that $\mathrm{P}$ and $\mathrm{V}$ would be on the right of $\mathrm{MeL}$, the size of the equilibrium set $=1-\mathrm{V}-\mathrm{MeL}$.

Illustrations. For the typical override rule of $2 / 3$ or $.66, \mathrm{~V}=1 / 3$ or .33 , and the size of the equilibrium set $=.50-.33=.16$. In other words, the maximum policy distance between the outcomes that can be expected in equilibrium in a non-party Congress submitted to $2 / 3$ override rule and the collectively efficient median legislator's preference encompasses only one sixth of the legislators' preferences.

For lower override rules, such as for example, $3 / 5$ or .60 , the size of the equilibrium set $=.10$. This is a smaller size of possible outcomes in equilibrium than with the $2 / 3$ rule, which suggests that, under a less demanding override rule, relatively more efficient policies located at less distance from the Median legislator's preference will be approved and be stable.

In the limit, if the rule to override the presidential veto were just a simple majority of legislators (as is the case in a few countries), the Veto legislator would coincide with the Median legislator. As a consequence, all possible presidential vetoes would be override and only the Median legislator's preference would become stable policy in equilibrium. In other words, with a simple majority override rule, the presidential veto can vanish, so as to make the President a non-pivotal actor and the legislative decision system close to a parliamentary one. We'll take these measurements as comparative references for results of alternative models based on the assumption that legislators are submitted to party discipline. 
In the light of the analysis just presented, in the non-party model of policy decision making in divided government optimum results could only be achieved if the President's preference was exactly the same as the Median legislator's. This makes the system of separation of powers inferior to the ideal model of parliamentary regime based on proportional representation, in which the Median legislator would correspond to the Median voter's preference and would always be included in a majority parliamentary decision. But, globally, the equilibrium outcomes that have been identified for a non-party institutional framework of separation of powers can be considered to be relatively satisfactory, since they either coincide with the Median legislator's preference or are located within a relatively small set of moderate preferences.

In this light, some claims for rejecting the acceptability of policy decisions made by inter-institutional processes such as those here stylized might be overstated, at least in comparison with some of the results to be found in other institutional settings of separation of powers such as those that will be discussed below. Underlying motivations for globally negative evaluations of the outcomes corresponding to the U.S. -like non-party model here presented may include a taste for non-decisive governments or a lucid awareness of the biases of the electoral system, or both. Indeed, to the extent that institutional pivotal actors are not faithfully representative of voters' preferences and their policy preferences are hazardous or narrowly localistic-oriented, the corresponding institutional policy decisions can be considered not socially satisfactory. Under those electorally based conditions, it might be preferable not to have an effective institutional framework for policy decisionmaking (and thus praise 'gridlock' for the sake of itself). However, to the extent that the preferences of political representatives in the institutions corresponded to voters' preferences thanks to an appropriate electoral system, the non-party model here revised suggests that the set of policy decisions to be made in equilibrium should bring about relatively low levels of social dissatisfaction. 


\section{Introducing political parties}

If disciplined political parties are substituted for the individual pivotal actors previously considered, both the relative distances among the new pivotal actors and the corresponding sizes of the equilibrium set will be markedly different. Two cases can be distinguished:

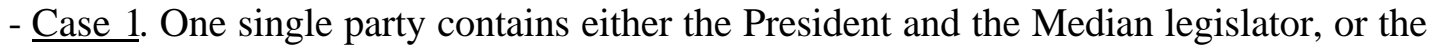
Veto legislator and the Median legislator, or the three pivotal actors. In all these situations, the expected outcomes are always coincident with the Median party's preference, whether it includes the President or not. When a Median party contains the Veto and the Median legislators, but not the President, the situation could be called 'unified congressional government'. When, in contrast, the Median legislator and the President belong to the same party, the President's party can reach its preferred outcomes in a similar way as it is supposed to occur in a situation of unified presidential government. Note that I am not implying here that the President's party has a majority of seats, which is usually considered the definition of unified government. Actually, the pivotal party only needs to be located on a sufficiently 'centrist' position and have more than $(\mathrm{MeL}-\mathrm{V}$ ) seats (e.g. for the $2 / 3$ override rule, one sixth of seats in Congress). What matters is the party's relative location in the spectrum so as to capture the key pivotal actors.

Some of these situations may be compared with the role of minority, 'centrist' governments in parliamentary regimes. Although they do not have a majority parliamentary support, they can survive if they include the median legislator and by this way split the opposition parties in two non-contiguous blocs on the opposite sides of the policy spectrum so as to make their joint action unfeasible (as analyzed by Strom 1990). Both in parliamentary and presidential regimes, a minority median party can legislate with collective efficiency in spite of not being the majority or perhaps even not the plurality party in number of legislators.

- Case 2. A party contains either the President or the Veto legislator (the more 'centrist' of these two actors) or both, while another party contains the Median legislator. This is the typical situation of divided government (again not identical to any situation in which no 
party, whether presidential or not, has a majority of seats). As will be discussed in the following paragraphs, it can be expected that, at least with two or a small number of parties, the distance between the Median party and the other pivotal parties will be larger than the distance between the pivotal actors in the previous assumption of party indiscipline. As a consequence, the equilibrium set will be larger and will contain more inefficient stable outcomes than in the previous model.

Figure 2 about here

Figure 2 illustrates the results in the assumption of two disciplined parties. For the sake of comparing the corresponding results, the preferences of the individual actors -- the President, the Veto legislator and the Median legislator-- are located as in the previous nonparty model. But now all of them support the preference of their party's median member, as the areas at the bottom of the graph suggest. Let's call the pivotal actors in this new setting Veto party, Vp, and Median party, Mep. As can be seen in the Figure, the Veto party's preference (which is the preference of the party's median member) is certainly more extreme than the individual Veto legislator's preference, and also, perhaps, more than the President's (or viceversa if the relative positions of the two actors are permuted). Likewise, the Median party's preference (which is the preference of the party's median member) is certainly more extreme than the individual Median legislator's preference. These results hold in the Figure for the position of the Median legislator at about half of the spectrum and the one of the Veto legislator as approximately corresponding to the override rule of $2 / 3$, but in qualitative terms they would hold for any variant of these rules such as those above mentioned.

Accordingly, the distance between the preferences of the pivotal actors is larger than in the non-party model. Analogously to the non-party model, and as can be seen in the Figure, the outcomes that can be expected in the two-party model from different status quos are the following: they correspond to the Median party (not the Median legislator) when the initial status quo is rather extreme or unsatisfactory, but now only from one of the extremes on the right side; they converge around the Veto party when the initial status quo is located 
on the other side; and they stay within the very large equilibrium set represented by the thick increasing line from a very large set of initial status quos.

The point is that the size of the equilibrium set in this model with two disciplined parties is larger than in the non-party model, thus containing more inefficient outcomes than in the former assumption. This can be seen in Figure 2 where the dotted line represents the set of expected outcomes, including the equilibrium set, as found under the assumption of no party discipline in Figure 1. It appears clearly that, under the same decision rules and pivotal actors' preferences, the set of equilibrium outcomes is more inefficient when party discipline matters: actually, almost no outcome coincides with the Median legislator's preference and a large interval of outcomes is pretty far away from that collectively efficient point. Now:

Equilibrium set $=\mathrm{Mep}-\mathrm{Vp}$

where:

Mep: Median party's preference;

Vp: Veto party's preference.

Proposition 2. Under the assumption of party democratic discipline, the equilibrium set, or set of stable outcomes, in a two party system includes all the policy positions between the Median party's preference and the Veto party's preference. This set is larger than the distance between the Median legislator's preference and the Veto legislator's preference, thus containing more inefficient stable outcomes than in the assumption that individual actors are not submitted to party discipline.

The size of the equilibrium set can be calculated more precisely. The number of seats of the Median party must be lower than the minimum amount of seats of the Veto legislator (which is one minus the override rule) and higher than half the seats: $1-\mathrm{V}>$ Mep seats > MeL.

Accordingly, the preference range of the Median party is the following:

$$
\mathrm{V}+(1-\mathrm{V}) / 2<\mathrm{Mep}<\mathrm{MeL}+\mathrm{MeL} / 2
$$


Consistently, the Veto party's number of seats must be higher than the veto rule, that is, one minus the override rule, and lower than half the seats: $\mathrm{V}<\mathrm{Vp}$ seats $<\mathrm{MeL}$.

Accordingly, the preference range of the Veto party is:

$\mathrm{V} / 2<\mathrm{Vp}$ preference $<\mathrm{MeL} / 2$

Now the size of the equilibrium set: Mep - Vp, can be calculated with the values of Mep and Vp just found. Any of the following two formulas is valid because they compare consistent pairs of values for each variable (minimum and maximum values for each):

Equilibrium set $=[\mathrm{V}+(1-\mathrm{V}) / 2]-[\mathrm{V} / 2]=1 / 2$

$\Leftrightarrow[\mathrm{MeL}+\mathrm{MeL} / 2]-\mathrm{Me} / 2=\mathrm{MeL}=1 / 2$.

It is thus found that in a two party system under the assumption of party democratic discipline previously presented, the size of the equilibrium set always encompasses half the legislators' preferences. As the previous ones, this result does not depend on the distribution of legislators' preferences along the policy space. With whatever distribution, the larger the size of the equilibrium set the higher is the proportion of potentially winning legislators' preferences that are away from the Median legislator's preference and, therefore, the lower the aggregate satisfaction with the corresponding outcomes.

Illustrations. This result holds for any override rule. For instance, for the typical $2 / 3$ rule, the size of the equilibrium set $=[.33+(1-.33) / 2]-[.16]=.50$. For the $3 / 5$ rule, the size of the equilibrium set $=[.40+(1-.40) / 2]-[.20]=.50$. For the $1 / 2$ rule, the size of the equilibrium set $=[.50+(1-.50) / 2]-[.25]=.50$

Let's explore now in which conditions a multiparty system with party discipline can produce a set of equilibrium outcomes as small and efficient as the one which can be expected when party discipline does not matter. This is equivalent to say that the preferences of the new pivotal actors, the Veto party and the Median party, must coincide with those of the Veto legislator and the Median legislator, respectively. 
Proposition 3. Under the assumption of party democratic discipline, a multiparty system can produce outcomes as efficient as in the assumption that party discipline does not matter if the distance between the Median party's preference and the Veto party's preference is equal to or lower than half the veto rule (which is one minus the override rule).

In order to calculate how many parties can be necessary to fulfill this condition, the reasoning is straightforward. Since the party preference is defined by its median member, the party encompasses the same number of legislators with preferences on the right of its median member as on its left. Thus, the two pivotal parties together must encompass at most the double of the legislators located in between the two parties' median members, which is equal to the veto rule (one minus the override rule).

This result would also hold if, in contrast to the example in the Figure, the seats to be gathered together by the two pivotal parties were distributed unevenly between them. In the limit, one pivotal party could have precisely the veto rule minus one seat and the other pivotal party just the pivotal seat, but their total joint distance would be the same.

Illustrations. For the typical 2/3 override rule, the total amount of seats of the two pivotal parties together must be equal or less than $1 / 3$. This certainly leaves room for at least one other party on the left and one other party on the right of the pivotal parties. In this case, the total number of parties will be at least four.

Figure 3 about here

Figure 3 illustrates the intermediate case in which the two pivotal parties have equal size, $1 / 6$ of seats each or 2/6 together. In this case, $3 / 12$ of the space lie on the left of the Veto party while 5/12 lie on the right of the Median party, apparently a sufficient room to allow other several parties to exist.

It may be interesting to ascertain how many parties would be necessary for one of the pivotal parties to be the plurality party in Congress -a position which is commonly associated to an initiative role. The answer is that, if the two pivotal parties have similar sizes, as in the example in the Figure, there should be at least other five parties located on 
the two extreme sections of the spectrum (two on the left and three on the right) so as that no party would have more than $1 / 6$ of seats. In total there should be at least seven parties in the system.

In other cases, the one third of seats to be gathered together by the two pivotal parties can be distributed unevenly between them. In the limit, one pivotal party could have precisely one third minus one seat and the other pivotal party just the pivotal seat. In this extreme case, for the larger pivotal party to be the plurality party, there should be at least other three parties (one on the left and two on the right) so as that no party would have more than $1 / 3$ of seats. In total there should be at least five parties, including the minute pivotal party.

\section{Concluding remarks}

I have presented a formal model of policy decision-making in an institutional regime of separation of powers in which the main actors are pivotal political parties with voting discipline. The model can be taken as a framework for analysis which may induce innovative revisions of empirical data, as well as new suggestions for institutional design. In this spirit, I will conclude with a few remarks on only three aspects that have been discussed in the paper: the concept of unified or divided government, the role of certain decision rules, and the consequences of the number of parties and their discipline on the effectiveness of policy decision-making. The examples included in the following paragraphs are chosen only to suggest the possibility of further empirical analyses. In future research, more systematic tests of the hypotheses developed here should select representative samples of cases, measure variables reliably, including the number of parties and the degrees of voting discipline, and conduct fair comparisons.

From the perspective provided by the pivotal actors theory, traditional distinctions between unified government and divided government based on whether the President's party has or not a majority of seats in Congress should be revised. In the assumption that legislators are not submitted to strong party discipline but can present bills and amendments and vote according to their individual preferences, unified government traditional senso 
never exists. In individually driven congresses, compromises have always to be reached between the President, the Veto legislator and the Median legislator in order to approve a bill.

In the alternative assumption that legislators are submitted to party discipline, a new type of 'quasi-unified' government can be defined which not only includes the traditional situation in which the President's party has a majority of seats but any other political party configuration in which the President's party controls the Veto legislator and the Median legislator. This allows the President's party to control the outcome of the legislative process in equilibrium, which may be expected to lie around the preference of the party's median member. This situation can exist even if the President's party has just above half the number of seats allowing him to sustain a veto. For instance, for the usual $2 / 3$ override rule, the President's party cancontrol all legislative outcomes in a similar way as a majority President with only $1 / 6$ of seats, if it is appropriately located around the 'center' of the policy space.

One of the implications of these new conceptualization of unified and divided government is that certain empirical comparisons of relative legislative and other decisionmaking performances during periods of traditionally-defined unified government and divided government in countries with low party discipline like the United States can be less interesting than previously assumed. Actually, the pivotal actors perspective can give an explanation to the finding that both situations tend to produce similar performances. (See Mayhew 1991, Fiorina 1992, Peterson and Greene 1993, Edwards, Barrett and Peake 1997, Epstein and O'Halloran 1999).

In contrast, the new perspective here presented highlights the interest of comparable studies on relative legislative performance in presidential regimes with strong party discipline. But with the warning that 'unified' and 'divided' government should be defined according to the insights offered by the pivotal actors model, especially considering party relative positions on the policy spectrum. (For an example of this kind of analysis, applied to Mexico, see Casar 2000).

A new situation deserves also to be identified for its likely relevant consequences on policy outcomes, one that can be called 'unified congressional government'. This appears when a single party includes the Veto and the Median legislators (with the just mentioned 
minimum amount of seats equal to half the veto rule), but not the President. This is a special case of divided government that can approach the more widely analyzed situation of centrist minority governments in parliamentary regimes. But in presidential regimes it may make the President extremely weak to the point to foster institutional conflicts focused on the President constitutional role.

A summary survey of recent developments in present Latin American presidential democracies suggests, for instance, that most of the Presidents with non-party or eccentric allegiance and extremely small legislative support (always below the veto rule) have ended in institutional conflict with the Congress: either being impeached (as Collor in Brazil in 1992 and Bucaram in Ecuador in 1997) or illegally dissolving Congress (as Fujimori in Peru in 1992 and Serrano in Guatemala in 1993) or resigning (as De la Rua in Argentina in 2001). Other small minority Presidents have survived thanks to having built consistent and broad electoral multiparty coalitions and maintained better ideologically-defined 'centrist' positions in Congress, especially in Brazil. (A summary of Latin American Presidents' legislative support, as measured by whether the President's party had either majority or veto sustaining share, can be found in Mainwaring and Shugart 1997: Tables 11.1 and 11.3. For discussion on the case of Brazil see Mainwaring 1999, Figueiredo and Limongi 2000, Ames 2001).

The consequences of different veto and override rules should also be different in settings with or without party discipline. When party discipline does not matter, the size of the equilibrium set is proportional to the threshold of the override rule. This means that, the higher the override rule --for instance $2 / 3$ as compared to $3 / 5--$, the larger the set of possible outcomes in equilibrium and, for the same distribution of legislators' preferences, the larger the distance between inefficient possible outcomes and the collectively efficient median legislator's preference. Other-than-veto rules able to increase the size of the equilibrium set can also be considered, as the filibuster cloture rule in the United States Senate included in Krehbiel's pivotal actors original model. Other qualified majority rules, such as the requirement of separate override thresholds in each of two non-congruent chambers in a bicameral Congress, should also be considered equivalent to increasing the override rule. Lower override rules can thus be advisable in order to reach more efficient outcomes. 
However, the effects of different rules can be less marked if legislators follow party discipline. A single party can, for instance, capture both the $1 / 3$ and the $2 / 5$ legislators, in which case changing the rule from $2 / 3$ to $3 / 5$ may not have any consequence on the identification of the pivotal actors, the size of the equilibrium set and the efficiency of the expected outcomes. The probability that a single party can control the Veto legislators corresponding to different veto rules is higher the smaller the number of parties. In a two party system with party discipline, changing the threshold of the veto rule may have no effect, unless the relative sizes of the parties change significantly. Institutional designers should, thus, take into account the number of parties and the levels of party discipline (which highly depend on electoral rules) at the time of choosing congressional decision rules. In fact, changing the key electoral inducements of bipartism and party discipline may be much more effective to improve the efficiency of decision-making than changing certain congressional decision rules.

The number of parties and their internal discipline at voting have revealed crucial to explain the effectiveness of institutions organized with separation of powers to make collectively satisfactory decisions. As specified in Propositions 1, 2 and 3 and the corresponding illustrations, the set of possible policy outcomes in equilibrium is smaller when party discipline does not matter than when it does. In the assumption of party discipline, the equilibrium set is smaller with a multiparty system than with a two party system (in the latter case the size of the equilibrium set always encompasses half legislators' preferences). Note that these results do not depend on the distribution of legislators' preferences along the policy spectrum but hold for any of these distributions.

These formal findings may have important implications for applied analyses. They can explain, for instance, that policy decision-making in the United States can be expected to be more difficult and unsatisfactory when party discipline increases --as was recently the case in the 1994-1998 period, in which harsh inter-institutional confrontation and conflict culminated in the impeachment of the President. (See, for instance, Campbell and Rockman 1999).

Also, a summary survey of presidential democracies in Latin America suggests that two-party systems can be distinguished along this line: while in Argentina very strong party discipline has promoted bipolar confrontation and conflict, in Costa Rica and Uruguay 
relatively high levels of party indiscipline and fractionalization have favored smoother decision-making processes. In other Latin American countries multiparty systems prevail, with varied levels of party discipline. (For party systems in Latin America, Jones 1995, Mainwaring and Scully 1995; for measurements of party discipline in a number of countries, including the four above mentioned, Mainwaring and Shugart, 1997: 421-429 and the corresponding country-chapters).

The survival of presidential democracies could also be enlightened with insights from the present model. Democratic successes and breakdowns have been hypothetically associated to different (effective) numbers of political parties, but empirical tests have not found conclusive evidence. In contrast, no systematic studies have yet developed that address the combined effect of the number of parties and their degree of discipline (or, for that matter, also the consequences of different veto rules), as suggested in the present paper.

In the light of the analyses here presented, legislators' individual freedom and multipartism appear as favorable institutional conditions for effective decision-making and collectively satisfactory policy outcomes in a framework of separation of powers. This conclusion may be against the grain of the (not very abundant) comparative literature on this specific matter, but the opposite hypothesis may have been excessively influenced by (more numerous) analyses of desirable features in parliamentary regimes. Somehow, congressional fragmentation can be a lenitive for the difficulties in decision-making created by separation of powers, checks and balances, and qualified-majority decision rules features that do not exist in parliamentary regimes. The argument can also be presented the other way around, focusing on the disadvantages of having a small number of strongly disciplined parties: if there are only two of these parties, it will be difficult for the President to work out deals with the opposition, and adversarial politics and gridlock will flourish. Indeed decision-making in situations of divided government can be relatively contentious and inflict legislators' and executive officers' significant bargaining and other transaction costs (aspects that have not been included in the model). However, two party indiscipline, as well as multipartism, can make decision making easier, promote less partisan confrontation, be more compromising, and favor more consensual and collectively efficient decisions than the opposite features. 
The last warning must be again on the effects of the electoral system. As

mentioned, all the above analysis has focused on 'collective' utility or satisfaction of policy outcomes based on political representatives' preferences. But it may differ from a calculus of 'social' utility based on voters' preferences due to distorting effects of electoral rules. It may be the case that the relatively high efficiency of the United States institutional system of decision-making -as can be enlightened by the pivotal actors model-- is hurt by biases in representation of the electoral system, while, in other countries, more representative electoral systems do not culminate in producing socially satisfactory policy outcomes due to drawbacks of the institutional process of decision-making. But this would be the subject for another work. 


\section{$\underline{\text { Notes }}$}

1. See, among others, Hammond and Miller 1987, King and Ragsdale 1988, Riggs 1988, Sundquist 1988, Linz 1990, Cox and Kernell 1991, Mayhew 1991, Fiorina 1992, Riker 1992, Shugart and Carey 1992, Cox and McCubbins 1993, Mainwaring 1993, Linz and Valenzuela 1994, Alesina and Rosenthal 1995, Jones 1995, Tsebelis 1995, Edwards, Barrett and Peake 1997, Mainwaring and Shugart 1997, Power and Gasiorowski 1997, Brady and Volden 1998, Nohlen and Fernández 1998, Colomer 2001, Haggard and McCubbins 2001, Lanzaro 2001.

2. Legislative paralysis or 'gridlock' may result not only from a standoff between the median and the veto legislators, as analyzed in the present article, but also from coordination problems or high bargaining and other transaction costs which are not addressed here. It could be argued that disciplined parties internalize some transaction costs and therefore reduce their influence on legislative decisions. But the assumption of zero transaction costs adopted in the present model may not be very realistic for certain institutional settings.

3. Krehbiel (1996: 27-32, and 1998: Chapter 8) himself discussed a possible extension of his analysis to settings with 'strong' parties. But he basically concluded that the explanation for lawmaking in the United States should "not to be found in a theory of party strength in legislatures" (1998: 185). Some of Krehbiel's analytical suggestions and insights are anyway taken for the present development.

4. The meaning of 'discipline' should not be mistaken. Even with highly undisciplined parties, most legislators of the same party vote together most times, but this is due to the fact that many legislative decisions have low salience or attract wide consensus. The levels of indiscipline are relevant when legislators deal with salient or highly divisive issues.

5. For further applications of the present analytical framework to other institutional settings, such as bicameral Congresses, an operative assumption would be that decisions are made 
not by simple majority but by some qualified majority rule, which can be equivalent to the requirement of simple majority in each of two politically non-congruent chambers.

6. Regarding Krehbiel's original model as presented for the analysis of the U.S. Congress, I omit the Senate filibuster cloture rule, a very peculiar U.S. rule.

7. However, the agenda setter can be decisive in order to select the policy issues on which decisions are going to be made, that is, to set the agenda in the narrowly literal sense of the term.

8. An alternative formula, which will not be discussed in the following pages, could imply the imposition of non-median leaders' preferences on all party members, including, for instance, the relative common situation of externally moderate, internally authoritarian party leaders, as well as the possibility that a President may 'buy' support or 'punish' lack of cooperation from his own party members through the distribution or refusal of pork and patronage resources. Depending on whether the leader-induced party preference were more moderate or more extreme than the party's median member, this modification would decrease or increase, respectively, the size of the equilibrium set.

9. The study of the United States Congress shows, however, that when the President's party has had a majority of seats, it has been more disciplined at voting than the minority party; see, for instance, King and Ragsdale 1988. 


\section{$\underline{\text { References }}$}

Alesina, Alberto and Howard Rosenthal. 1995. Partisan Politics, Divided Government, and the Economy. New York: Cambridge University Press.

Ames, Barry. 2001. The Deadlock of Democracy in Brazil. Ann Arbor: The University of Michigan Press.

Brady, David and Craig Volden. 1998. Revolving Gridlock. Boulder, Co: Westview Press.

Cameron, Charles M. 2000. Veto Bargaining. Presidents and the Politics of Negative Powers. New York: Cambridge University Press.

Campbell, Colin and Bert A. Rockman eds. 1999. The Clinton Legacy. New York: Chatham House.

Casar, Maria Amparo. 2000. 'Coaliciones y cohesión partidista en un congreso sin mayoría: la Cámara de Diputados de México, 1997-1999', Política y Gobierno, VII, 1: 183-202.

Castles, Francis and Mair, Peter, 1984: "Left-Right Political Scales: Some Experts Judgements", European Journal of Political Research, 12: 83- 88.

Colomer, Josep M. 2001. Political Institutions: Democracy and Social Choice. New York: Oxford University Press.

Cox, Gary Samuel and Kernell. 1991. The Politics of Divided Government. Boulder: Westview.

Cox, Gary and Matthew D.McCubbins. 1993. Legislative Leviathan: Party Goverment in the House. Berkeley: University of California Press

Davis, Otto A., Melvin J. Hinich, and Peter C. Ordeshook. 1970. 'An Expository Development of a Mathematical Model of the Electoral Process', American Political Science Review, 64: 426- 48.

Edwards, George C., Andrew Barrett, and Jeffrey Peake. 1997. 'Legislative Impact of Divided Government', American Journal of Political Science, 41, 2: 545- 563.

Epstein, David and Sharyn O'Halloran. 1999. Delegating Powers: A Transaction Cost Politics Approach to Policy Making under Separate Powers. New York: Cambridge University Press.

Figueiredo, Angelina Cheibub and Fernando Limongi. 2000. 'Presidential Power, Legislative Organization, and Party Behavior in Brazil', Comparative Politics, 32, 2: 151- 170 .

Fiorina, Morris. 1992. Divided Government. New York: Macmillan.

Haggard, Stephan and Matthew D. McCubbins eds. 2001. Presidents, Parliaments, and Policy. New York: Cambridge University Press.

Hammond, Thomas H. and Gary J. Miller. 1987. 'The Core of the Constitution', American Political Science Review, 81: 1155-74.

Hinich, Melvin J., and Michael C. Munger. 1997. Analytical Politics. New York: Cambridge University Press.

Huber, John D., and G. Bingham Powell, Jr. 1994. 'Congruence Between Citizens and Policymakers in Two Visions of Liberal Democracy', World Politics, 46, 3: 291326.

Huber, John D., and Ronald Inglehart. 1995. 'Expert Interpretations of Party Space and Party Locations in 42 Societies', Party Politics, 1, 1: 73-111. 
Jones, Mark P. 1995. Electoral Laws and the Survival of Presidential Democracies. Notre Dame, Ind.: University of Notre Dame Press.

King, Gary and Lyn Ragsdale. 1988: The Elusive Executive: Discovering Statistical Patterns in the Presidency. Washington: Congressional Quarterly.

Krehbiel, Keith. 1996. 'Institutional and Partisan Sources of Gridlock: A Theory of Divided and Unified Government', Journal of Theoretical Politics, 8: 7-40.

Krehbiel, Keith. 1998. Pivotal Politics: A Theory of U.S. Lawmaking. Chicago: The University of Chicago Press.

Lanzaro, Jorge ed. 2001. Tipos de presidencialismo y coaliciones políticas en America Latina. Buenos Aires: CLACSO.

Linz, Juan, 1990. 'The Perils of Presidentialism', Journal of Democracy, 1, 1: 51 - 69.

Linz, Juan and Arturo Valenzuela eds. 1994. The Failure of Presidential Democracy. Baltimore: The Johns Hopkins University Press.

Mainwaring, Scott. 1993. 'Presidentialism, Mutipartism, and Democracy: The Difficult Combination', Comparative Political Studies, 26: 198- 228.

Mainwaring, Scott. 1999. Rethinking Party Systems in the Third Wave of Democratization: the Case of Brazil. Stanford, Ca.: Stanford University Press.

Mainwaring, Scott and Timothy Scully eds. 1995. Building Democratic Institutions. Party Systems in Latin America. Stanford: Stanford University Press.

Mainwaring, Scott and Matthew S. Shugart eds. 1997. Presidentialism and Democracy in Latin America. New York: Cambridge University Press.

Mayhew, David R., 1991. Divided We Govern: Party Control, Lawmaking, and Investigations, 1946-1990. New Haven: Yale University Press.

Nohlen, Dieter and Mario Fernández B. eds. 1998. El presidencialismo renovado. Caracas: Nueva Sociedad.

Peterson, Paul E., and Jay P. Greene. 1993. 'Why Executive-Legislative Conflict in the U.S. Is Dwindling', British Journal of Political Science, 24: 33-55.

Poole, Keith T. and Howard Rosenthal 1997. Congress: A Political-Economic History of Roll-Call Voting. New York: Oxford University Press.

Powell, Jr., G. Bingham. 2000. Elections as Instruments of Democracy: Majoritarian and Proportional Visions. New Haven: Yale University Press.

Power, Timothy J., and Mark J. Gasiorowski. 1997. 'Institutional Design and Democratic Consolidation in the Third World", Comparative Political Studies, 30, 2: 123-155.

Riggs, Fred W., 1988. 'The Survival of Presidentialism in America: Para-constitutional Practices", International Political Science Review, 9, 4: 247- 278.

Riker, William H., 1992. 'The Justification of Bicameralism', International Political Science Review, 13, 1: 101-116.

Shugart, Matthew S., and John M. Carey. 1992. Presidents and Assemblies. Constitutional Design and Electoral Dynamics. Cambridge: Cambridge University Press.

Strom, Kaare. 1990. Minority Government and Majority Rule. New York: Cambridge University Press.

Sundquist, James L. 1988. 'Needed: A Political Theory for the New Era of Coalition Government in the United States', Political Science Quarterly, 103: 613-35.

Tsebelis, George, 1995. 'Decision Making in Political Systems: Veto Players in Presidentialism, Parliamentarism, Multicameralism, and Multipartyism", British Journal of Political Science, 25: 289-326. 


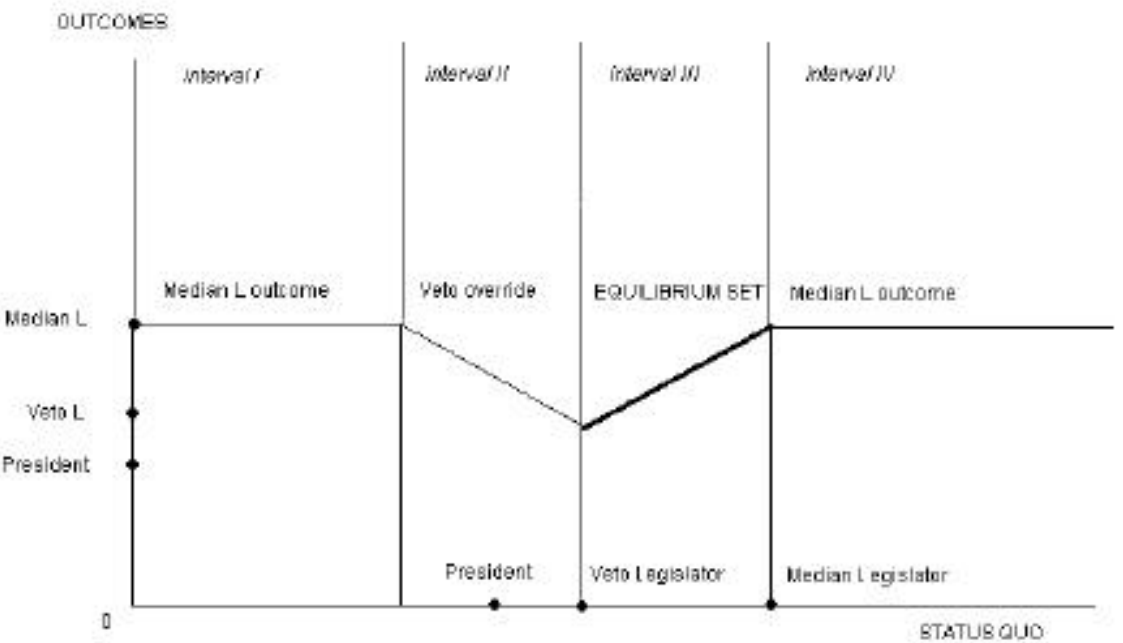

Finure 1. Equilibrium potcies in the phodal polities theory with no parties 


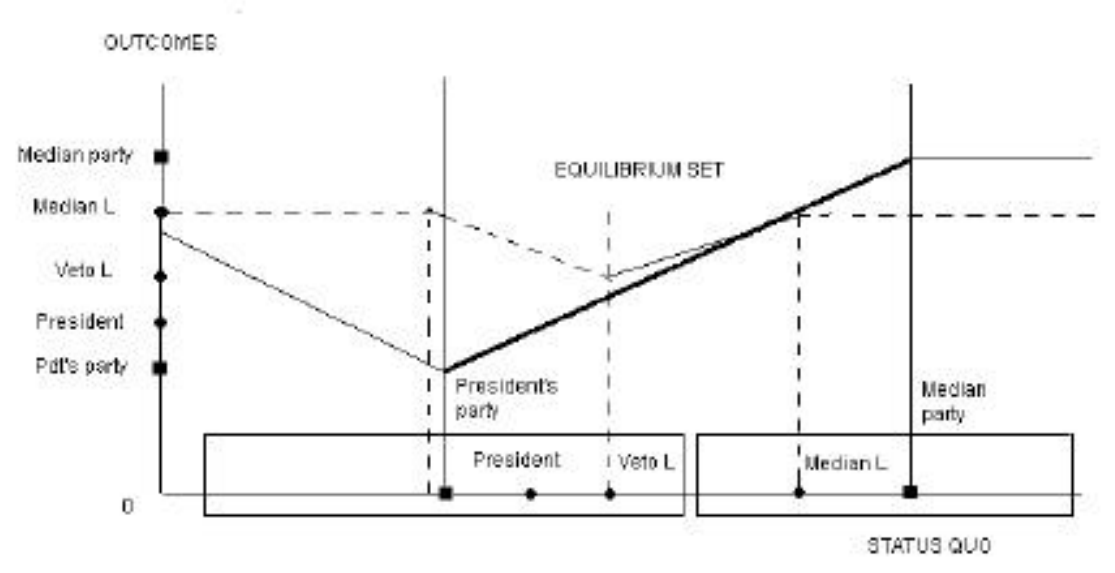

Figure 2. Equilibrium policies with two disciplined parties 


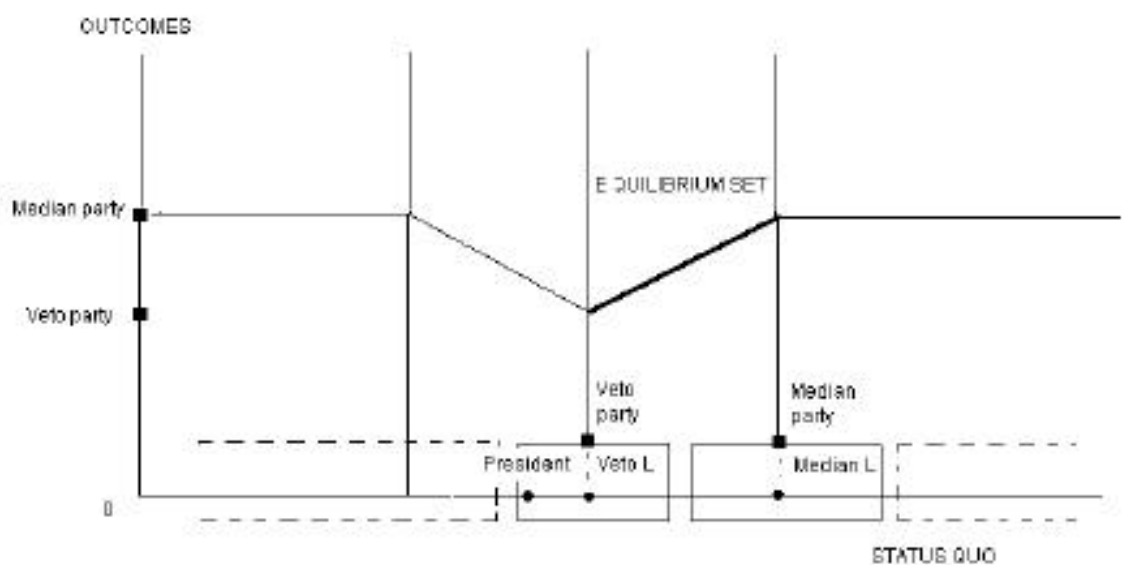

Fiture 3. Equilibrium potcies with mutipte disciplined parties 